\title{
Climate-based daylight analysis of fixed shading devices in an open-plan office
}

Paula M. Esquivias, Carmen M. Muñoz, Ignacio Acosta, David Moreno and Jaime Navarro

This is an Accepted Manuscript of an article published by SAGE Journals:

Lighting Research and Technology, Volume 48, 2, 2016, Pages 205-220,

ISSN 1477-1535

https://doi.org/10.1177/1477153514563638

(c) (1) (9) 


\title{
Authors' names and affiliations:
}

Paula M. Esquivias ${ }^{a}$, Carmen M. Muñoz ${ }^{a}$, Ignacio Acosta ${ }^{a}$, David Moreno ${ }^{a}$, Jaime Navarro ${ }^{a}$

a Instituto Universitario de Arquitectura y Ciencias de la Construcción (IUACC), Universidad de Sevilla, Spain

\section{Corresponding Author:}

Paula M. Esquivias, Instituto Universitario de Arquitectura y Ciencias de la Construcción (IUACC), Universidad de Sevilla, Spain

Email: pesquivias2@us.es

\begin{abstract}
Office buildings consume large amounts of energy and are responsible for a large part of greenhouse gas emissions worldwide. Among building energy efficiency measures, solar shading plays a significant role in reducing building cooling energy consumption. This study analysed the influence of solar protection on daylighting of an open-plan office. Climate-based daylight modelling (CBDM) was used to predict such as Daylight Factor (DF), Daylight Autonomy (DA) and Useful Daylight Illuminances (UDI).
\end{abstract}

The results obtained showed that overhangs, and horizontal and vertical louvers have a similar behaviour and sidefins have no relevance to indoor daylight conditions. In all cases it has been proven that excessive obstruction may yield an excessive reduction in a range of illuminances between 500 and 2000 lux, increasing lighting energy consumption.

Keywords: Climate-based Daylight Modelling, DAYSIM, fixed shading devices, overhang, sidefins, fixed louvers

\section{Introduction}

The Energy Performance of Buildings Directive (EPBD) highlights the importance of reducing energy consumption in buildings, given that this represents up to $40 \%$ of the total energy consumption in the European Union (1). In Mediterranean climates, where there are many hours of solar radiation, there is a great amount of available daylight but it is not usually used in its entirety (2). In fact, in Spain, artificial lighting consumption accounts for up to $30 \%$ of total electric consumption in office buildings (3).

Adequate natural light and design of the buildings, as passive strategies for buildings which take into account climate and local conditions, are becoming increasingly important in the energy 


\section{Climate-based daylight analysis of fixed shading devices in an open-plan office}

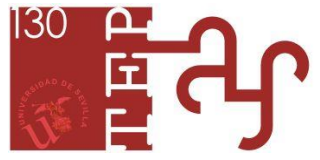

performance of buildings to improve indoor thermal conditions, especially in summer, thus allowing size and energy requirements for air conditioning systems to be reduced (1) (4).

However, problems associated with glare and visual discomfort are inevitable when direct solar radiation is transmitted into the room. In addition, the amount of solar radiation represents one of the most significant sources of overheating, especially during summer (5). Solar shading devices block solar radiation, preventing glare and controlling direct solar gains (6) (7) (8). Solar shading devices come in a wide variety of types and shapes, can be located inside, outside or within the envelope of a building (8) (2) and can be fixed or movable. Unlike fixed shades, operable ones are dependent on how building occupants operate them (9) or on the performance of dimming controls (10) (11).

Movable shading devices can be adjusted on changing outdoor conditions and are more effective in controlling sky diffuse radiation, since fixed devices only block a certain part of the sky vault and the performance of the movable ones is based on changing the portion of the sky vault blocked (12). Since 1970, several publications have appeared on the interaction of office workers with respect to the use of window shade systems, mainly Venetian blinds (7) (9) (13), attempting to establish a universal pattern for the prediction of building performance, as window blind operation affects thermal and visual environments. The development of control elements has prompted many papers aiming to determine a predictive model for the proper position of louvers, or for those controlled by workers (14) (7). Previous studies investigated the effect of shading devices and their impact on daylight quantity and distribution (10), energy use (8) (4) and human comfort and perception (6) (5) (11).

The occupants' actions also add considerable uncertainty in predicting how a building will perform at the design stage (7) (9). In fact, an all too common scenario in overglazed buildings is for the blinds to be down to control glare and the lights to be on (15). Current automated shade controls often fail to recognise when conditions worsen or change to undesirable, with shades moving to a less desirable position (7). An approach to solar shading design which eliminates much of the uncertainty deriving from users and controls performance is the use of fixed shading devices (i.e. overhangs, sidefins, fixed louvers).

Fixed shading devices use static geometry and materials' optical properties alone to reduce direct solar radiation entering a building (16), while admitting high levels of diffuse solar radiation, often deeper into the space (17). Fixed shading devices may reduce increasing thermal loads during summer while controlling intense summer daylight, improving vision and reducing glare (9) (18). However, in winter they also may block a significant amount of solar radiation. This reduction of the 


\section{Climate-based daylight analysis of fixed shading devices in an open-plan office}

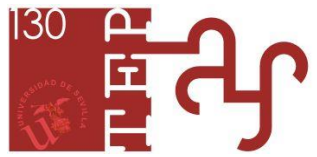

solar heat gains would decrease the internal loads, increasing the heating energy consumption (6). They also have a major effect on the appearance of a building, meanwhile blocking part of the view to the exterior (5).

Each face of a building requires a different shading treatment as sunlight strikes each side from different angles (19). Any fixed horizontal shading device applied on non-south façades is less effective in reducing solar gains because it would have to be excessively deep to block direct solar radiation at low solar altitudes (20), whereas the use of these shading devices is essential for southoriented façades, especially in Mediterranean climates (18). For this reason, buildings with wider north- and south-facing façades are preferable wherever the site allows (21), according to Bellia et al. (4), who highlighted how the depth of the overhangs on the south side depends on the window height. Although the vertical fins proved to be more efficient in the northern, eastern and western façades, for the southern façade, the combined shade devices turned out to be more efficient than simple devices (22).

In this regard, works like those carried out by David et al. (23) study the effect of different proposals of overhangs and sidefins. For example, rectangular sidefins significantly reduce the level of luminance of the room in comparison with triangular sidefins, and the best solar protection for the case study is clearly an overhang with an infinite width and a relative length equal to 1 (the length of the solar shading is equal to the height of the window). Other authors like H.H. Alzoubi (24) also study the impact on indoor daylight of vertical and horizontal louvers, focusing on energy savings and quality of lighting. The results of the simulations carried out for the $21^{\text {st }}$ of June at 12 pm showed that vertical louvers can provide both good daylighting and minimum energy needs for fulfilling the IESNA requirements.

External shading devices such as overhangs, louvers and egg crates should be encouraged, given their significant impact on improving internal thermal conditions. However, in the study by Al- Tamimi and Fadzil (19), egg crate devices were the best for reducing indoor air temperature and decreasing the number of discomfort hours due to their configuration (i.e. combination of overhang and fin devices), which avoids solar radiation from varied sun angles.

León et al. (25) studied the potential reduction in energy demand of the most common types of solar protection: overhangs, sidefins, fixed and mobile horizontal louvers and mobile exterior blinds. They stressed that the influence of horizontal overhangs was most significant for south-facing façades and insignificant for the others, particularly north-facing façades. However, the use of horizontal louvers significantly reduced global energy needs for all geographic orientations except north. The reduction percentages varied between approximately $10 \%$ for the east and $14 \%$ for the west. 


\section{Climate-based daylight analysis of fixed shading devices in an open-plan office}

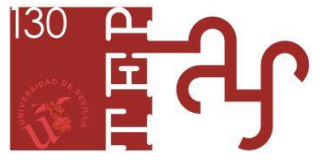

Aldawoud (5) noted that the performance of external shading devices differs depending on the design and size of these devices. Sizing overhangs and fins is crucial for ensuring the proper function especially when both are combined. Well-designed overhangs and vertical fins form a key shading strategy to reduce overheating and cooling loads during summer months.

Due to a lack of studies about the impact of fixed solar protection in the daylight performance of buildings and considering the possibility of analysing daylight conditions throughout the year with the most common Dynamic Daylight Metrics (Daylight Autonomy and Useful Daylight Illuminances) (26), this study was proposed to examine the relative impact of fixed solar protection in the daylight performance of office buildings. It is also an attempt to give architects and engineers involved in buildings awareness about this design decision.

\section{Methodology}

This study was executed with computer simulations using the validated RADIANCE-based program DAYSIM 3.1.b (27) (28). DAYSIM uses the Daylight coefficient method developed along with the Perez All-Weather Sky model to efficiently calculate illuminance distributions for each of the sensors defined for the work plane under all sky conditions throughout a year (27) (29). By defining an annual schedule and a minimum illuminance on the workplane, DAYSIM calculates the Daylight Factor (DF), Daylight Autonomy (DA) and Useful Daylight Illuminances (UDI), as well as other daylight metrics.

Although the limitations of DF have been widely reported (26) (31), it is important to know how representative Daylight Factor is - based on diffuse illuminance - for the local climate, as there is still some discussion as to whether Daylight Factor should continue to be used or dynamic daylight metrics should be taken up instead (30) (29). DF does not include any contributions from sunlight or take the orientation of the glazed surface into account, due to the characteristics of the CIE Overcast Sky. Furthermore, while its simplicity constitutes its major advantage, the CIE Overcast Sky model used for DF does not allow us to consider the variability of annual daylight in the space under study.

Climate-based Daylight Metrics allow us to establish the annual daylight amount for a given space using hourly or sub-hourly calculations of the illuminance of every sensor point placed usually on the workplane (32). Both Daylight Autonomy (DA) and Useful Daylight Illuminance (UDI) are metrics that make possible to process a large amount of daylight illuminance data (up to 4380 hourly values matching the number of daytime hours for hourly calculations) for each sensor point. Both metrics analyse the illuminance data by establishing a time range, regarding diurnal occupancy of a space, and a suitable illumination level for the execution of visual tasks (26) (32). 


\section{Climate-based daylight analysis of fixed shading devices in an open-plan office}

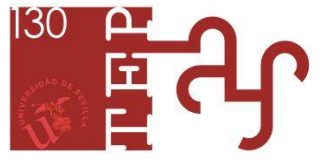

Daylight Autonomy is defined as the percentage of the year during which there is a minimum threshold of illumination provided only by daylight (26). The purpose of Useful Daylight Illuminance is to determine when daylight levels are of use to the user. It is currently measured using three metrics to express the time percentage in which the following illuminance ranges are obtained: Less than $100 \mathrm{~lx}$ (very dark), more than $2000 \mathrm{~lx}$ (excessive light) and a useful range of between 100 and 2000 Ix (26).

Despite 3000 lux is being fixed as the upper limit and the useful range is being splitted in two (33), the upper illuminance threshold may change as more accurate information correlating glare and illuminance is known. Studies indicate that in practical situations, daylight illuminances greater than 2000 lux are considered too high for occupants' comfort - both visual and thermal, so that this work maintains 2000 lux as upper threshold (31).

\subsection{Reference office model}

The model under study is an open-plan office measuring $20 \mathrm{~m} \times 12 \mathrm{~m} \times 3.5 \mathrm{~m}$ located in Seville (latitude $37.42^{\circ} \mathrm{N}$, longitude $5.6^{\circ} \mathrm{W}$ ). The weather file used for calculations (IWEC) has been downloaded from the EnergyPlus weather data website and contains data recorded at San Pablo Airport (Seville).

Openings are distributed in two opposing façades. On each façade there are 6 windows measuring $1.35 \mathrm{~m} \times 0.90 \mathrm{~m}$ each, with a sill-height of $1 \mathrm{~m}$, giving a window-to-wall-ratio of $17.50 \%(10 \%$ window-to-floor-ratio). There are no interior partitions and the glazing has a high visible transmittance. Although the authors placed work stations parallel to the glazed façades, their location is not fixed, so the whole area is treated as the task area.

The workplane is $0.80 \mathrm{~m}$ from the floor, with sensor points every $0.20 \mathrm{~m}$ (Figure 1). There is a minimum distance of $0.5 \mathrm{~m}$ between sensors and walls to avoid edge effects. Table 1 shows the optical characteristics of the model. 


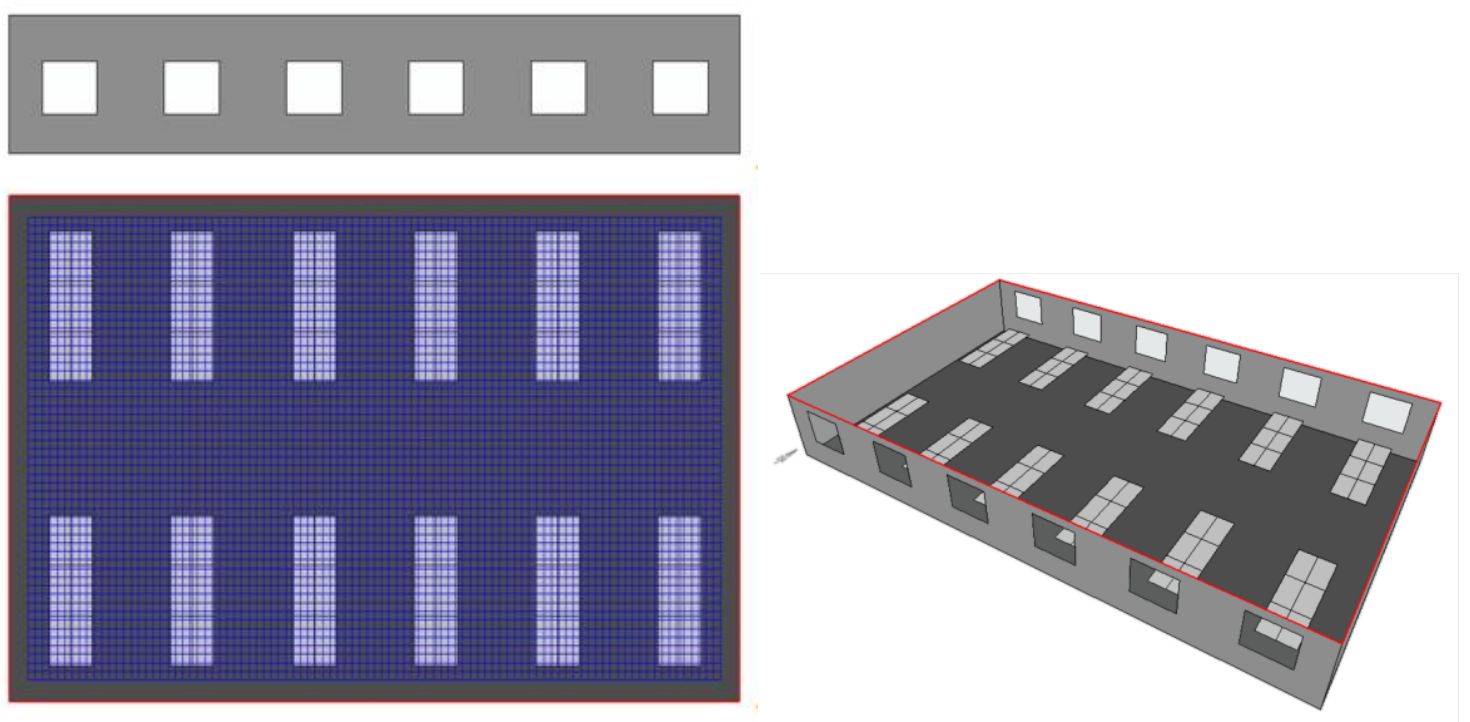

Figure 1. Reference open-plan office model: plan and perspective

\begin{tabular}{ll}
\hline Initial conditions & \\
\hline Glazing visible transmittance & $90 \%$ \\
\hline Floor reflectance & $30 \%$ \\
\hline Ceiling reflectance & $75 \%$ \\
\hline Wall reflectance & $55 \%$ \\
\hline Furniture reflectance & $35 \%$ \\
\hline Ground reflectance & $20 \%$ \\
\hline
\end{tabular}

Table 1. Optical characteristics of case study.

\subsection{Lighting requirements of office spaces}

In order to calculate the dynamic daylight performance metrics it is necessary to define the time range for which they will be calculated, as well as the minimum light level desired. Given that the space analysed is an office, the time range under study is from 8:00 $\mathrm{h}$ to 18:00 $\mathrm{h}$. As regards the minimum light level, European Standard EN 12464-1 on Lighting of Workplaces (34) suggests an average maintained illuminance of $500 \mathrm{~lx}$ within the working area for office tasks.

In terms of DF, an average maintained illuminance of $500 \mathrm{~lx}$ can be understood as the minimum DF value necessary to obtain this level of indoor illumination, considering outdoor illuminance with an annual frequency of $50 \%$ in the time range specified.

This value is obtained from the IWEC weather data for Seville by calculating the cumulative curve for available diffuse horizontal diurnal illuminance from 8:00 h to 18:00 h (Figure 2), so represents the diffuse contribution for all sky types occurred during a year. The value for diffuse exterior illuminance for $50 \%$ of the year is equal to 19800 lux. This value gives a DF of $2.53 \%$ to obtain an internal illuminance of 500 lux. 


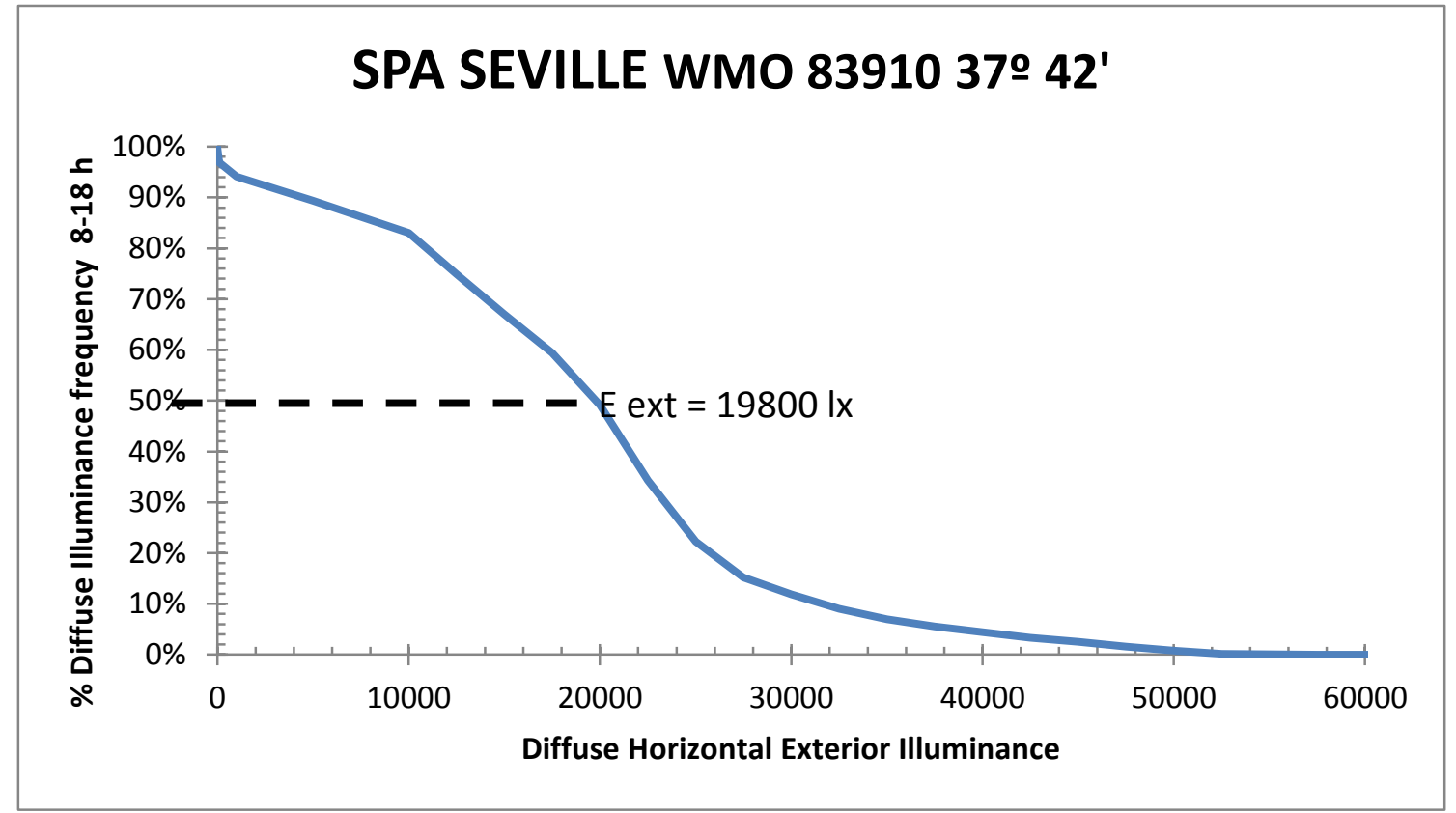

Figure 2. Cumulative curve of diffuse horizontal Illuminance from 8:00 h to 18:00 h. Values taken from the EnergyPlus weather climate file for Seville (Spain).

In terms of DA for the calculation range considered, an average maintained illuminance of $500 \mathrm{~lx}$ requires the determination of the time percentage in which each point exceeds this minimum lighting value. Once DA values for each point have been established, the percentage of sensors of the workplane with a DA of $50 \%$ or above can be calculated.

\subsection{Proposals}

Four series of fixed shading devices were considered to evaluate their influence on indoor daylight environment. Each series was coded with letters and numbers according to the dimensions and variables of each protection type. Fixed protections, such as horizontal overhangs $(\mathrm{HO})$, vertical sidefins (VF), Horizontal louvers (HL) and Vertical louvers (VL) with a reflectance of $55 \%$ were analysed while varying their primary dimensions in order to block different portions of the sky vault: $0^{\circ}$ (without obstruction), $15^{\circ}, 30^{\circ}, 45^{\circ}$ and $60^{\circ}$ of obstruction (Table 2).
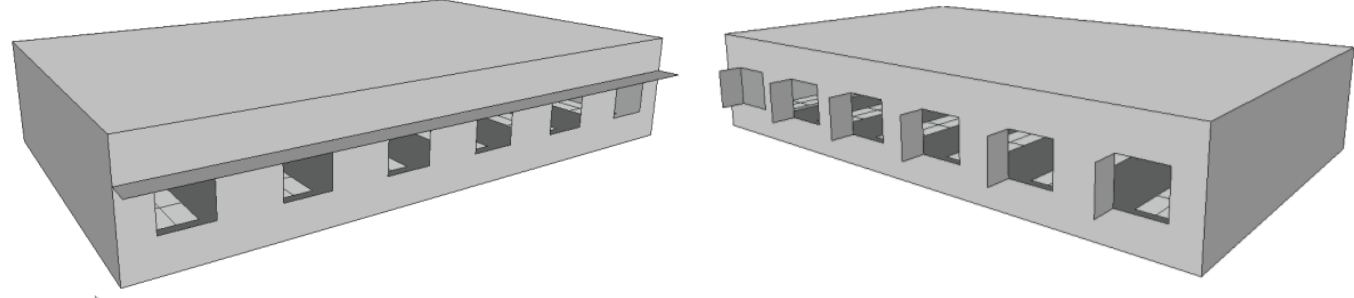

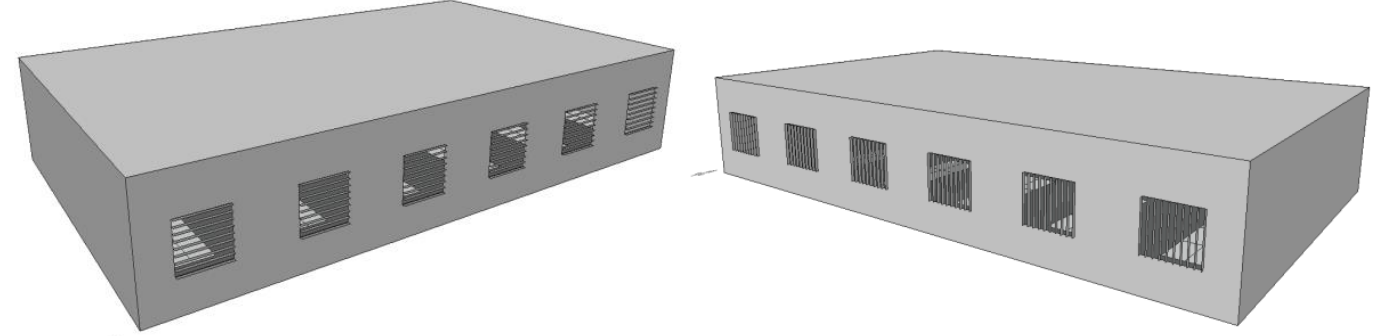

Figure 3. (a) Overhang, (b) Vertical sidefins, (c) Horizontal louvers, (d) Vertical louvers.

In this study, solar shading devices are orthogonal to the façade so their obstruction angle are determined by the depth of each element or, maintaining a certain depth as in the case of louvers, by the distance between them.

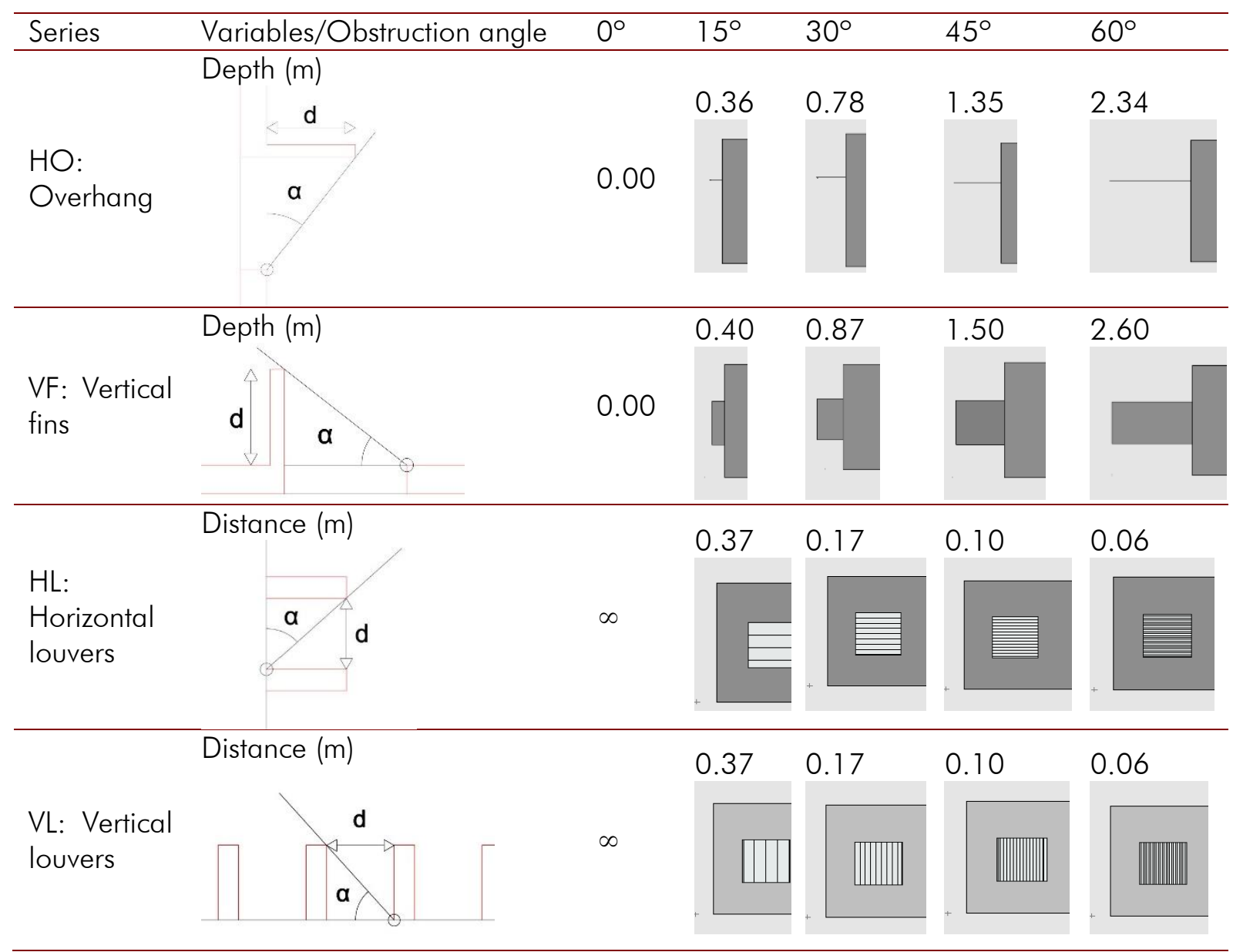

\section{Table 2. Sizes of fixed shading devices proposed}

For all proposals, the reference model has been defined as a no shading model, without solar protection. Two different orientations were considered for the reference model to study the effect of the shading devices in the four cardinal orientations. Given that the opposing glazed façades of the original reference model faced north and south, the model was also rotated $90^{\circ}$ to consider east- 
and west- facing glazed façades. The shading devices were applied separately to the south, east and west façades, and were applied in pairs to the north-south and east-west façades (Table 3).

\begin{tabular}{|c|c|c|c|c|c|}
\hline \multirow{2}{*}{ Element } & \multicolumn{3}{|c|}{ Singular Parent façade } & \multicolumn{2}{|c|}{ Two parent façades } \\
\hline & South & East & West & $\mathrm{N}-\mathrm{S}$ & E-W \\
\hline Overhang $(\mathrm{HO})$ & $\mathrm{HOSS}$ & $\mathrm{HOE}$ & $\mathrm{HO} W$ & $\mathrm{HON}-\mathrm{S}$ & $\mathrm{HO} \mathrm{E}-\mathrm{W}$ \\
\hline $\begin{array}{l}\text { Vertical fins (VF), } \\
\text { facing }\end{array}$ & $\begin{array}{l}\text { East: EoS } \\
\text { West: WoS }\end{array}$ & South: SoE & South: SoW & $\begin{array}{l}\text { East: EoNS } \\
\text { West: WoNS }\end{array}$ & $\begin{array}{l}\text { South: } \\
\text { SoEW }\end{array}$ \\
\hline $\begin{array}{l}\text { Horizontal louvers } \\
(\mathrm{HL})\end{array}$ & HL_S & HL_E & HL_W & $\mathrm{HL} \_\mathrm{N}-\mathrm{S}$ & HL_E-W \\
\hline Vertical Louvers (VL) & VL_S & $V L \_E$ & VL_W & VL_N-S & VL_E-W \\
\hline
\end{tabular}

Table 3. Application of shading devices and orientations

In the case of vertical sidefins, these face south on the east (SoE) and west (SoW) façades, and were also studied separately facing east (EoS) and west (WoS) on the south façade. Moreover, vertical sidefins applied in two façades facing south on the east and west façades (SoEW), and facing east (EoNS) and west (WoNS) on the north and south façades were studied.

\section{Results}

The values of the Daylight Factor, Daylight Autonomy and Useful Daylight Illuminances for every sensor of the workplane were calculated for each model. This was followed by the calculation of the percentage of grid sensors above $2.53 \%$ DF and $50 \%$ DA, needed to reach 500 lux during $50 \%$ of the time range and the average of UDI distribution values for each range. These values are presented in groups for each type of solar protection studied: overhangs, vertical sidefins, horizontal louvers and vertical louvers, comparing the results of each model within the group with the results of the reference model.

The results of the original open-plan office in Seville, with north-south glazed façades and no obstructions, are shown in Table 4. The difference between considering only diffuse exterior illuminance or including the direct component for the period of time specified is reflected in the difference in DF and DA criteria values, representing almost $50 \%$ of the workplane of difference. Most of the workplane remains within the comfort range (100-2000 lux) and only an average of $30 \%$ remains outside this range.

\begin{tabular}{ll}
\hline Initial conditions: Results & \\
\hline DF criterion & $42.76 \%$ \\
\hline DA criterion & $93.96 \%$ \\
\hline UDI < 100 lux & $15.26 \%$ \\
\hline UDI 100-2000 lux & $73.21 \%$ \\
\hline UDI > 2000 lux & $11.52 \%$ \\
\hline
\end{tabular}

Table 4. Results for the original open-plan office. 


\subsection{Overhang}

Figures 4 and 5 show the results obtained for the different overhang depths studied, expressed in relative terms with regard to the original model. The values are ordered from lowest angle of obstruction to highest as follows: $0^{\circ}, 15^{\circ}, 30^{\circ}, 45^{\circ}, 60^{\circ}$.

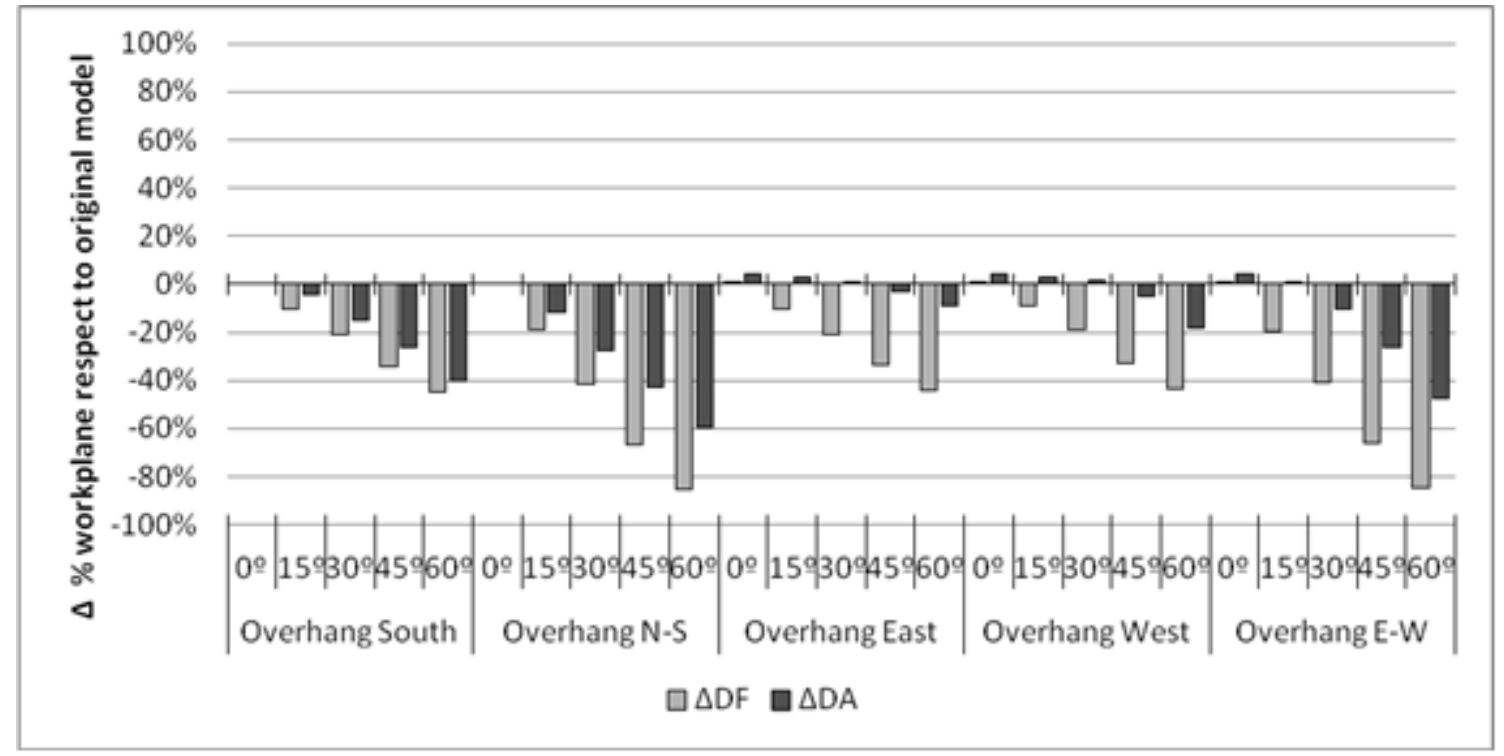

Figure 4. DF and DA differential results for overhangs.

Given the limitations of the DF, as shown in Figure 4, the results obtained for the different orientations do not vary. As the angle of obstruction increases, the proportion of the workplane in compliance with the set criterion decreases, resulting in a reduction of $45.1 \%$ compared with the reference model when applied to a single façade and a reduction up to $85.1 \%$ if overhangs are fitted on both glazed façades, given the greater reduction of the sky vault visible by windows.

DA is also progressively reduced as the angle of obstruction of the overhang increases. It is practically correlated when applied on two façades and squared in the case of overhangs only installed on a single façade, since the other façade is maintained as a source of daylight.

This is why the overhang in the south-facing façade is more efficient in blocking solar radiation and results in a reduction of up to $40 \%$ of the area of the workplane, exceeding the criterion established with respect to the original model, and up to $60 \%$ if also installed in the north-facing façade. The overhang in the east-facing façade alone has the least incidence in terms of DA, with a reduction of only $9 \%$ with respect to the values obtained without solar protection. 


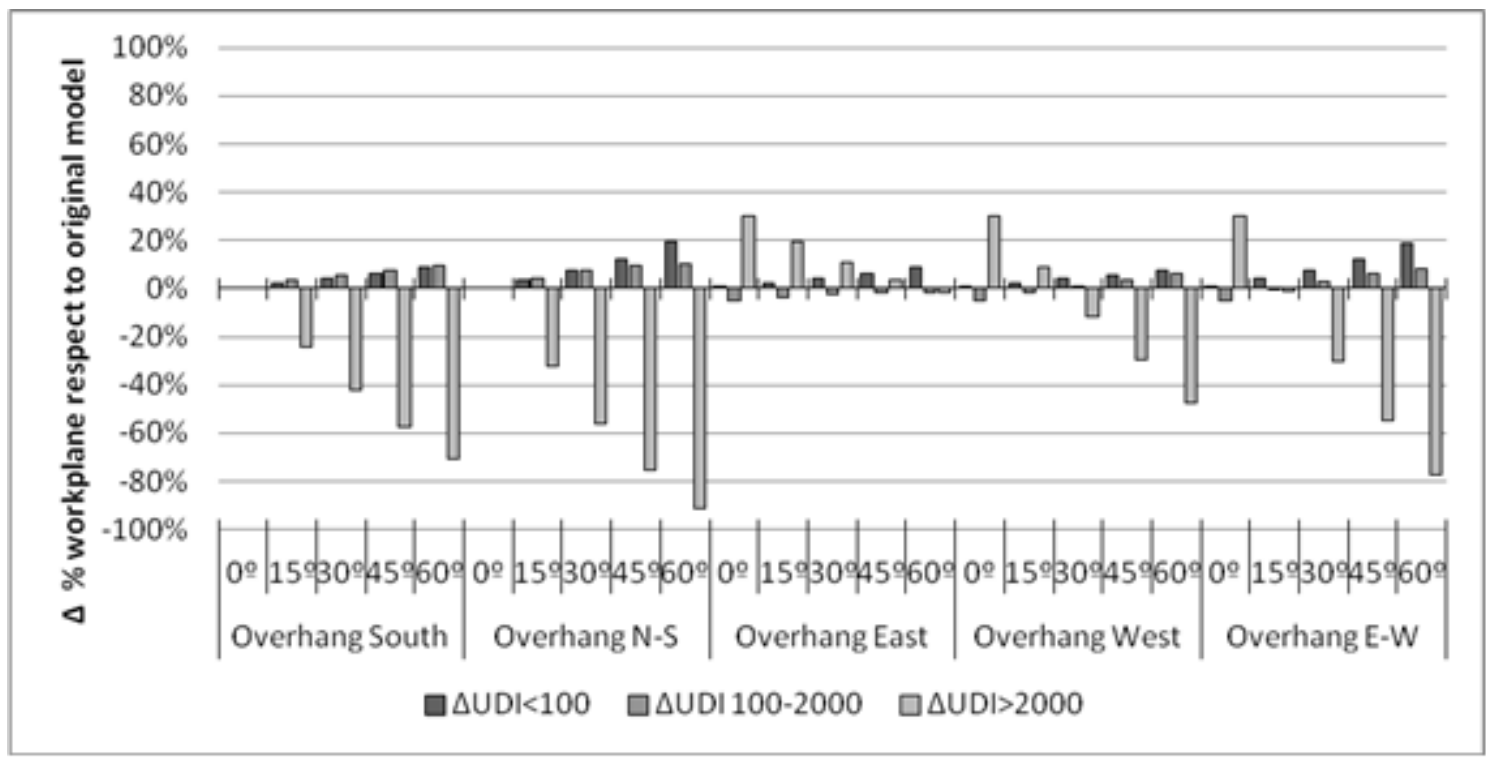

Figure 5. UDI differential results for overhangs.

While DF and DA decrease as the angle of obstruction increases, the proportion of the workplane in a useful illuminance range increases by $10 \%$ for overhangs on the south- and west-facing façades. If the overhang is added to the east-facing façade the increase is $3 \%$. If overhangs are fitted on both glazed façades there is a $10 \%$ increase in both cases.

In the case of the percentage of the workplane with illuminances below 100 lux, as the angle of obstruction is increased, there is a linear increase of around 10\% if applied to a single façade, resulting in the same behaviour for the three options studied. This increase is close to $20 \%$ if an overhang is added to both façades, with no variations depending on orientation.

As regards UDI $>2000$, the results show a linear decrease with the depth of the overhangs; the most efficient overhang is on the south-facing façade, eliminating the proportion of workplane surface with excessive illuminance.

The least reduction is observed for the overhang on the east-facing façade, with the highest obstruction of solar radiation on a surface of around 10\%; it is most effective when combined with the protection of the west-facing façade.

The results show that the overhangs fitted on the south-facing façade, alone or in combination with overhangs on the north-facing façade, are most effective when reducing excessive illuminance in spaces. In fact, although there is a major reduction in DA, the results of UDI 100-2000 show that most of the workplane surface remains between 100 and 500 lux, and may require additional artificial lighting. 
It is also concluded that, considering the location and the set working hours, there is greater incidence of solar radiation during the afternoon than during the morning, and therefore any strategy applied to the east-facing façade is barely relevant in global behaviour.

\subsection{Sidefins}

The results obtained for the different proposals with sidefins are shown in Figures 6 and 7

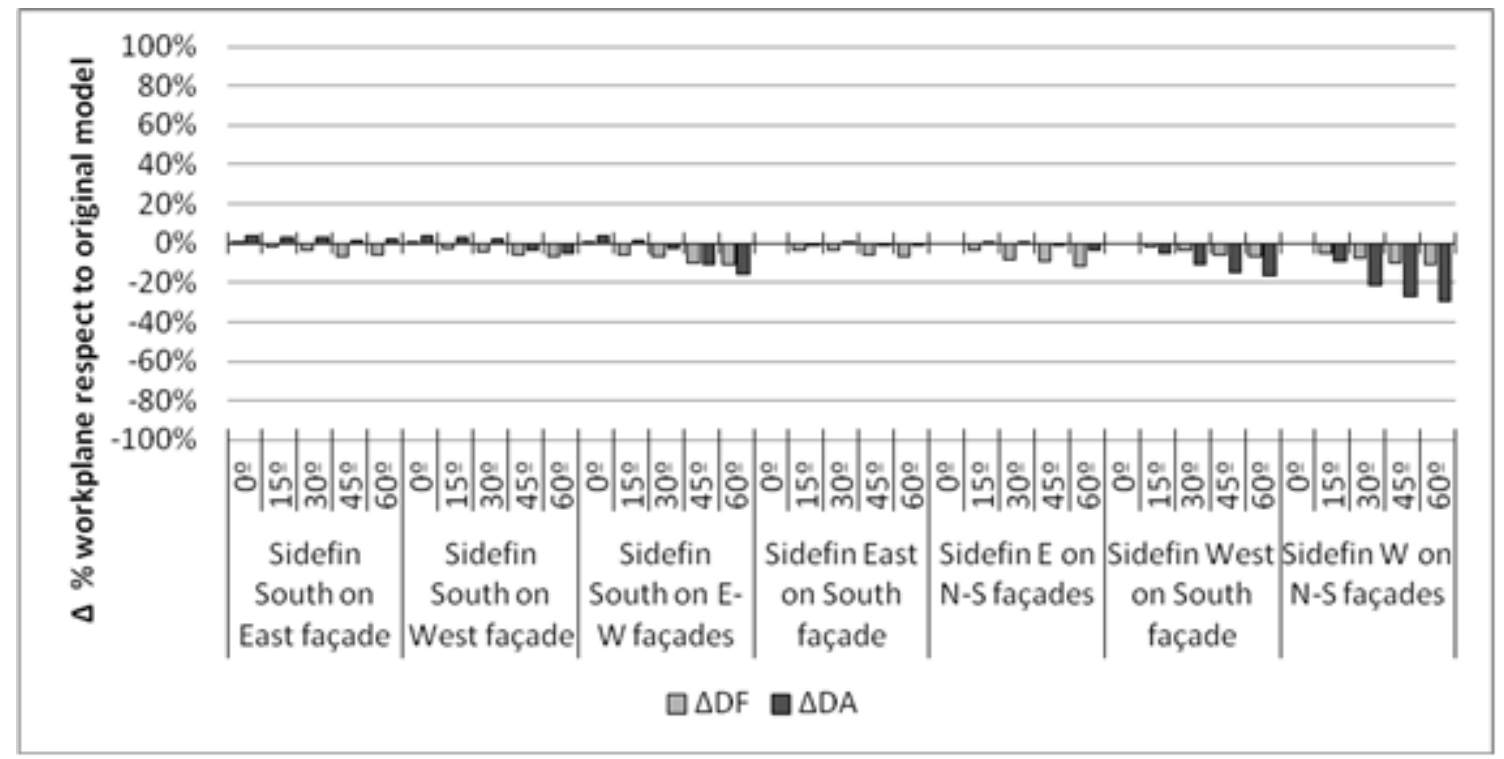

Figure 6. DF and DA differential results for sidefins.

As seen in Figure 6, the presence of solar protections has little influence on the DF, and the workplace surface exceeding the established criterion remains mainly as the original model for all cases, although it decreases slightly as the depth of the sidefins increases.

As regards DA, the most effective strategies for blocking direct sunlight are those which protect the openings of the south-facing façade to the west, resulting in a reduction of up to $16 \%$, and the incorporation of protection to the west of the north- and south-facing façades, where there is a reduction of up to $30 \%$. The strategies with the least incidence are those that protect the openings of the east-facing façade and the addition of sidefins towards the east on the north-and south-facing façades. 


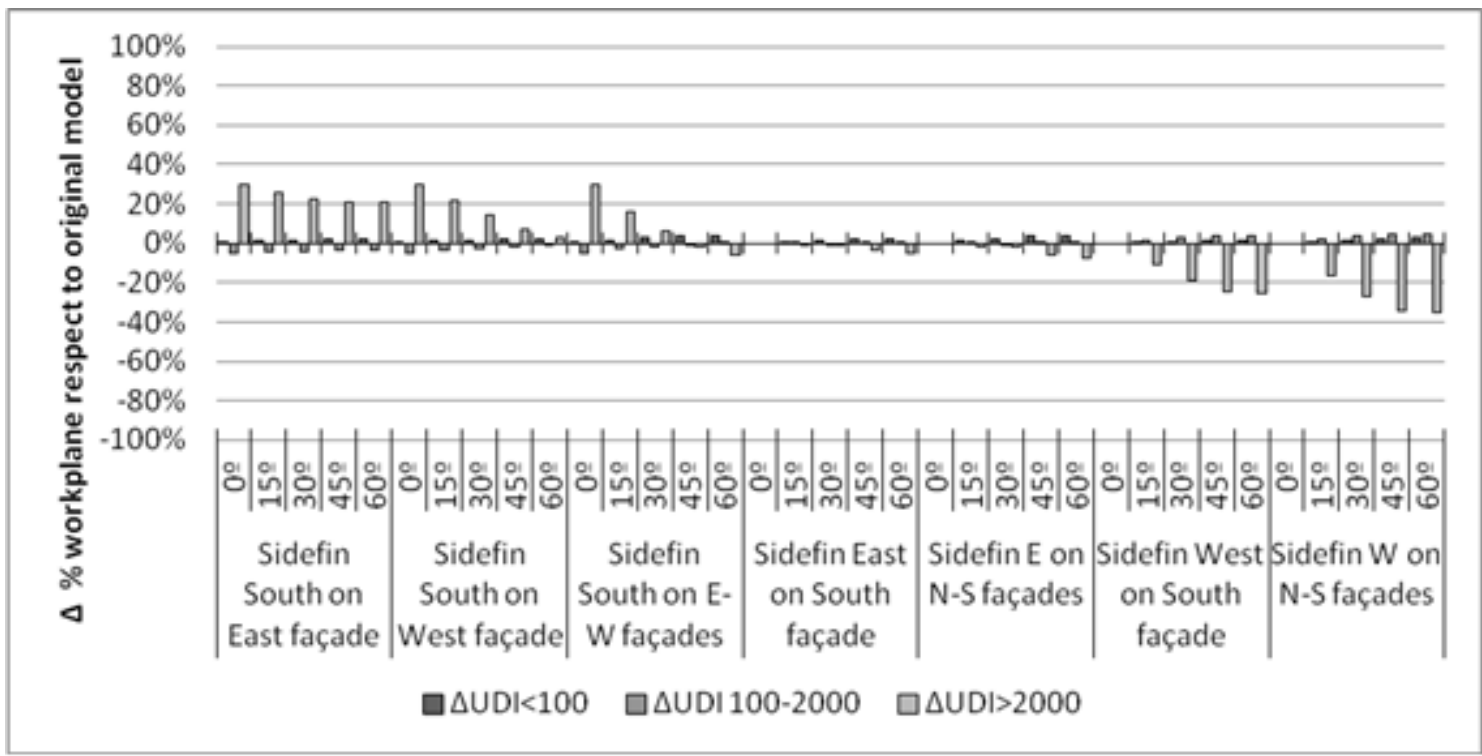

Figure 7. UDI differential results for sidefins.

Although there is a slight increase of useful illuminance values, in all cases the surface remains at around $73 \%$, with around $15 \%$ of the surface with illuminance below 100 lux and a slight decrease in values relating to excessive illuminance.

In general it can be stated that incorporating sidefins barely has an effect on the extreme illuminance ranges. The most notable effect occurs in the illuminance range between 500 and 2000 lux, given that the presence of sidefins reduces DA, but with the UDI results, this reduction increases the points of the calculation surface in a range of illuminance between 100 and 500 lux, and additional artificial lighting is required.

\subsection{Horizontal and vertical louvers}

The results for the horizontal louvers can be seen in Figures 8.a and 8.b, while Figures 9.a and 9.b show those for vertical louvers. In these cases, the depth remained constant and the distance between louvers was modified to obtain different angles of obstruction. 

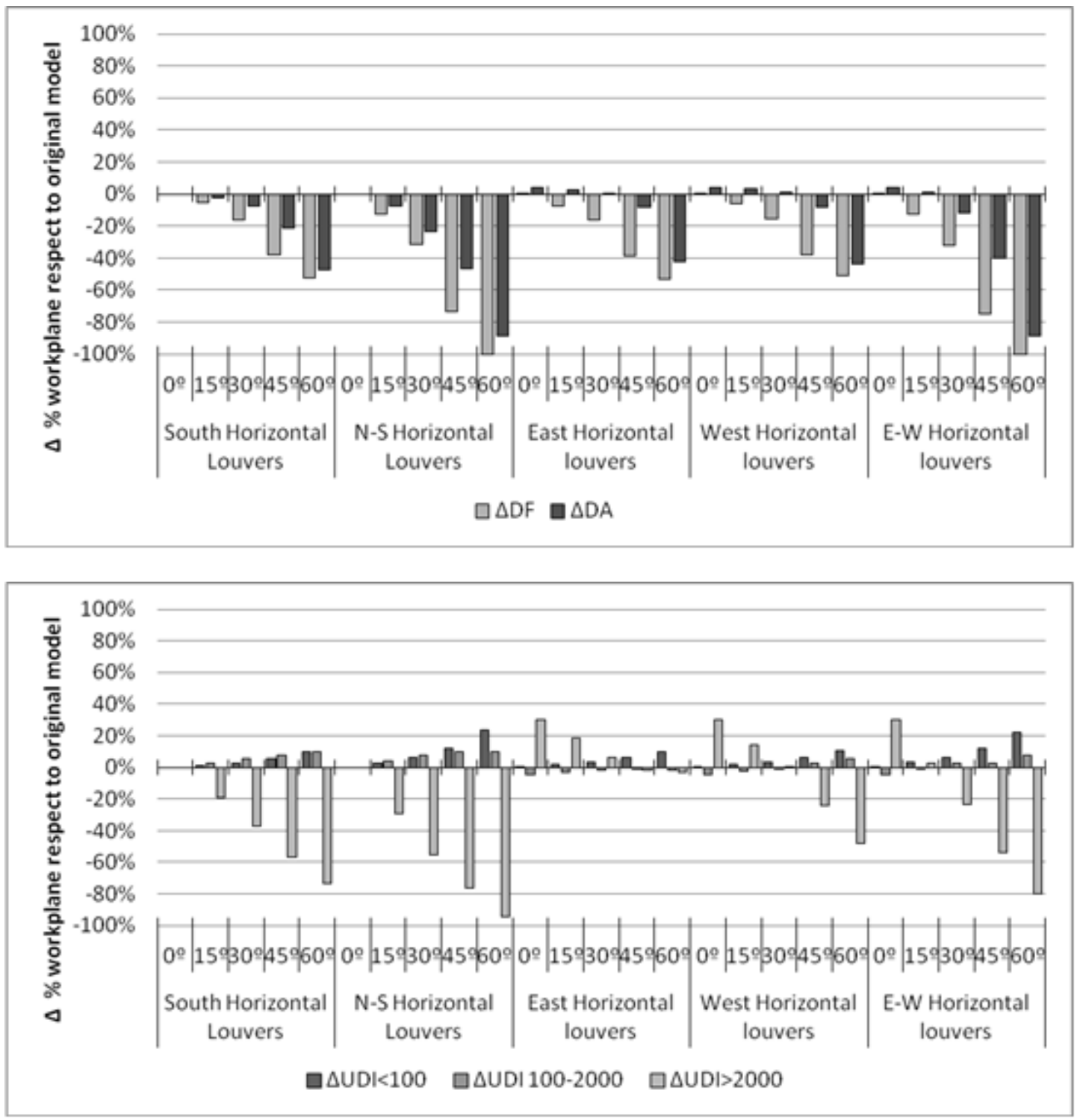

Figure 8. (a) DF and DA differential results for horizontal louvers. (b) UDI differential results for horizontal louvers.

When horizontal louvers are incorporated, their influence on the daylighting conditions exhibits similar behaviour as regards DF, and also similar to the UDI with the addition of overhangs, both when added to a single façade and to two glazed façades.

As regards DF there is greater emphasis on the reduction of the workplane exceeding the set criterion, being this reduction up to $50 \%$ for a single façade and $100 \%$ when fitted on both façades. In the case of the UDI values, the differences obtained with overhangs are maintained, according to the façade and obstruction angle, and with slight variations of no significance.

In the case of DA, compared with the addition of overhangs, the presence of horizontal louvers presents the greatest differences for the higher angles of obstruction. When applied to a single 
façade, all cases exceed the criterion established, even with the greatest obstruction angle. However, if these are added to both façades the reduction in DA is much more pronounced and produces a reduction that is excessive for the $60^{\circ}$ angle of obstruction, so the maximum angle of obstruction should be $45^{\circ}$.
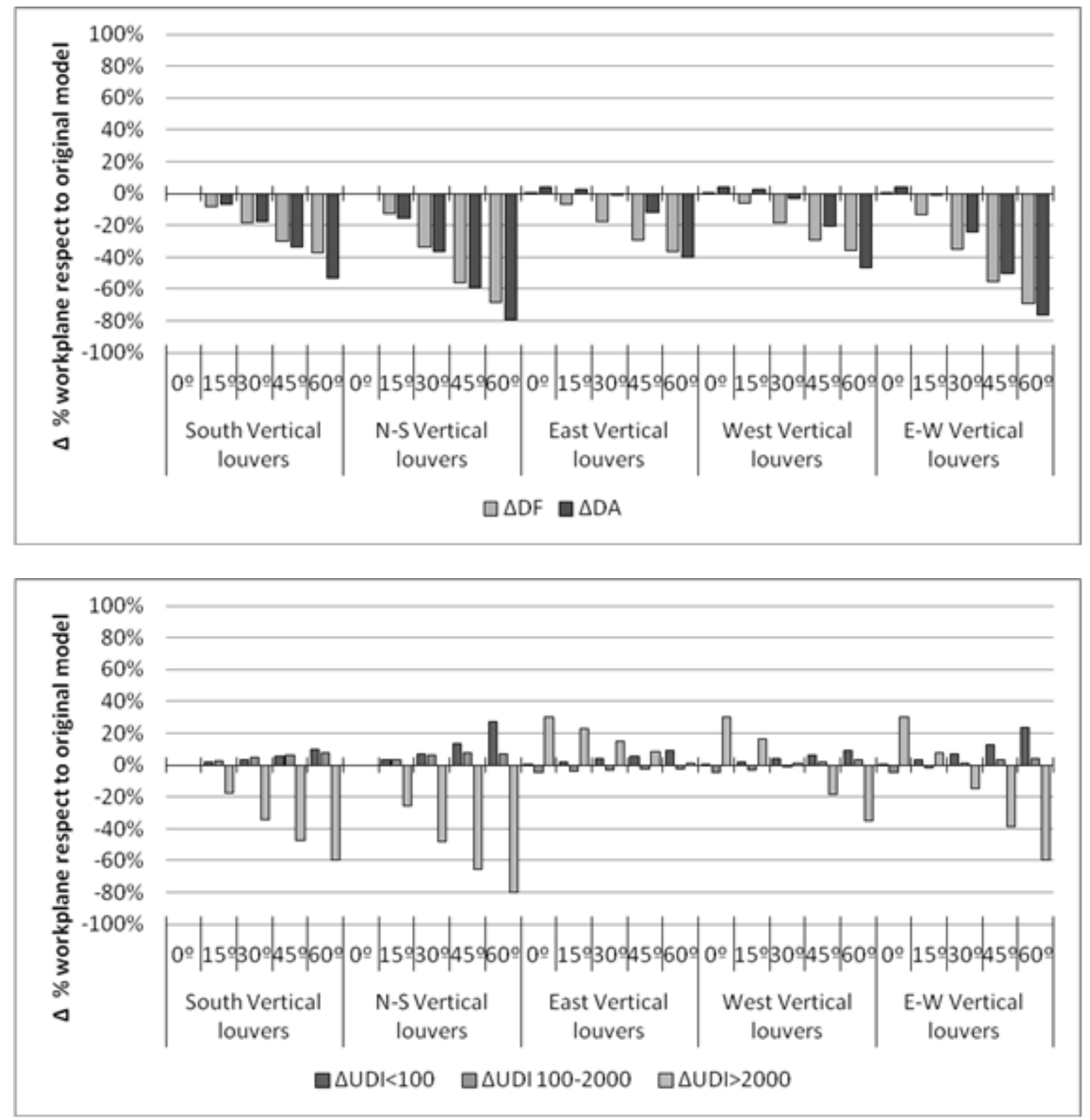

Figure 9. (a) DF and DA differential results for ventical louvers. (b) UDI differential results for vertical louvers.

As regards the incorporation of vertical louvers, its influence on the daylighting conditions differs from the results obtained using sidefins. Although some tendencies remain, these have more pronounced slopes, both when incorporated on a single façade or on both glazed façades. DA differences show the greatest variations compared with the results of the sidefins. 


\section{Climate-based daylight analysis of fixed shading devices in an open-plan office}

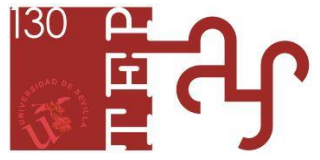

According to the established DF criterion, applying vertical louver provide a greater reduction respect to the original model, without shading devices, than using sidefins and this reduction is more pronounced when applied on both façades.

In addition, there are barely significant variations in UDI values with the incorporation of vertical louvers to the east or west, except for differences in the reduction of UDI>2000, where the louvers on the façades cause the least reduction in the workplane with excessive illuminance.

As regards DA, the presence of vertical louvers on the south-facing façade causes major reductions. When it is also placed on the north-facing façade it shows a linear behaviour, so that minimum requirements are not reached for high levels of obstruction. Thus the recommended limit for the obstruction angle is $30^{\circ}$.

Similar behaviour, although not as noticeable, can be observed in cases with vertical louvers on façades facing east or west, or both directions simultaneously. In the case of the vertical louvers, the reduction in DA contributes to increasing the portion of the workplane between 100 and 500 lux and to a more noticeable increase in $\mathrm{UDI}<100$.

\section{Discussion and conclusions}

As well as emphasising the influence of local climate conditions in establishing strategies to reduce energy demand, and in view of the increasing cooling consumption, the European Directive on Energy Efficiency in buildings highlights as priorities those strategies aimed at reducing energy demand in summer.

In this respect, solar protections are elements that reduce the amount of sun exposure of spaces, blocking the entry of a high intensity heat source: solar radiation. In addition, the incorporation of solar protections can be executed during the useful life of buildings, making it a strategy to be considered not only during the design phases for new buildings, but also in the energy refurbishment of existing ones.

However, we must bear in mind that solar radiation is also a source of lighting, making it necessary to suitably design and study the solar protections so that they do not have a negative effect on daylighting conditions and cause an increase in artificial lighting consumption.

Until relatively recently, solar charts were the most frequently used tools to provide information on the effectiveness of solar protections, and since DF does not consider direct illuminance and generally uses a cylindrically symmetrical luminance distribution of the sky vault for calculation, it only offers information on the loss of diffuse illuminance, or the loss of sky vision, due to the presence of solar protections. 


\section{Climate-based daylight analysis of fixed shading devices in an open-plan office}

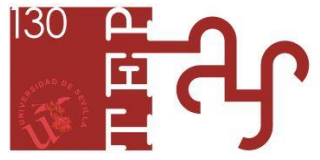

Solar charts are also basic tools for the correct design of solar protections based on solar geometry, strengthening inherited knowledge or the golden rules which state that the west orientation is the most challenging as regards protection, followed by the east orientation, where vertical louvers are advised. In the case of south-facing façades the best strategy is the incorporation of horizontal louvers. However, solar charts depend on the latitude of the point of study and do not provide information on the intensity of solar radiation, thermal and luminous, which reaches a point.

After a decade daylight metrics based on climate-based simulations are starting to be considered the basis for future building guidelines, and it is thought that these one-parameter studies are initial steps in that direction. It should also be noted that this paper refers to Seville, so the optimal energy solutions are different from those of other locations, whose cold climates usually require high solar gains in winter and therefore have little or no need for fixed shading devices for buildings (4).

The study of the different proposals made it possible to verify that the most effective solar protections for blocking direct solar incidence on the spaces are based on horizontal elements, like overhangs and horizontal louvers, found on south-facing façades even in the case they are applied in combination with north-facing façades. The least effective protections are those based on vertical elements, like sidefins and vertical louvers, especially if they are installed to protect an opening from solar exposure from the east, that is to say, morning radiation, at least in Seville, where solar exposure in the afternoons is much more intense.

Incorporating solar protections on a single façade or on both glazed façades produces a linear increase in the percentage of the workplane within the useful illuminance range, between 100 and 2000 lux. Depending on the case, this percentage is between $70 \%$ and $80 \%$. This variation of around $10 \%$ is generally reflected in a decrease in surface area with excessive illuminance (UDI>2000), with between 15 and $20 \%$ of the surface area with illuminance below 100 lux during the period considered.

Despite the practically minimal variations in useful illuminances, the results in DA show the greatest variations. In all cases, there is a reduction in the surface in excess of 500 lux during $50 \%$ of the time range studied, as the angle of obstruction is increased, to a greater or lesser degree depending on the case. When the solar protections are applied on only one façade, this surface is almost always greater than $50 \%$.

However, when incorporated on the two glazed façades of the models, this tendency remains for overhangs and sidefins. In the case of the louvers, for high angles of obstruction, the reduction is excessive, and in these cases distances between louvers which provide obstruction angles above $30^{\circ}$ are not recommended. 


\section{Climate-based daylight analysis of fixed shading devices in an open-plan office}

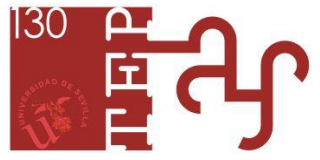

Although the presence of solar protections can cause drastic reductions in the autonomous surface, this reduction is not reflected as noticeably on UDI variations, indicating that solar protections reduce the surface with illuminance between 500 and 2000 lux, generally increasing the surface with an illuminance between 100 and 500 lux, and thus requiring complementary artificial lighting.

It can be observed that the incorporation of overhangs and horizontal and vertical louvers results in approximately the same effects as regards the surface in useful range with excessive or insufficient daylight. The reduction in surface with autonomy also follows the same tendency in all three cases, and is less noticeable when incorporating overhangs. In view of this, and given that the effects are similar, choosing between one types or another may be determined beforehand by architectural design considerations.

However, this study proposes basic solar protection devices, although there are in fact more complex protections that will be studied in greater depth in future, basing their efficiency on their depth or on the surface obstructed, as a double skin. Of course, mobile shading devices have been widely studied but as they depend on occupants' behaviour and/or dimming controls they introduce such an uncertainty and lie outside what the authors consider building conditioning and its relationship with building design.

\section{Funding Acknowledgments}

This paper presents part of the results obtained during the development of the Subtask "Ergonomic analysis of lighting conditions in work or study places" for the TECNOCAl research project (Efficient and smart technologies oriented to healthy and comfortable interior environments), contracted for Acciona Infraestructuras, S.A. [C.P.1168, CGT 0010] within the Industrial R\&D Initiative CENIT, funded by the Ministry of Science and Innovation. This Subtask was carried out in the Institute of Architecture and Building Science (IUACC) of the University of Seville by members of the TEP-130 research group. The authors are grateful for the technical and financial support provided and wish to thank all those involved for their valuable collaboration.

\section{References:}

1. Directive 2010/31/EU on Energy Performance of Buildings. 2010.

2. Lim Y-W, Ahmad, MH and Ossena DR. Internal Shading for efficient Tropical Daylighting in Malaysian Contemporary High-Rise Open Plan Office. Indoor Built Environ. 2012; 000: 1-20.

3. Ministerio de Industria, Turismo y Comercio. Plan de Acción 2008-2012 de la Estrategia de Ahorro y Eficiencia Energética en España. 2007. 


\section{Climate-based daylight analysis of fixed shading devices in an open-plan office}

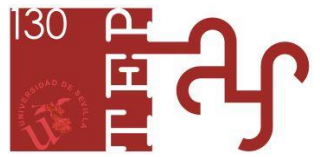

4. Bellia L, De Falco F and Minichiello F. Effects of solar shading devices on energy requirements of standalone office buildings for Italian climates. Appl. Therm. Eng. 2013; 54: 190-201.

5. Aldawoud A. Conventional fixed shading devices in comparison to an electrochromic glazing system in hot, dry climate. Energy Build. 2013; 59: 104-110.

6. Yao J. An investigation into the impact of movable solar shades on energy, indoor thermal and visual comfort improvements. Build. Environ. 2014; 71: 24-32.

7. O'Brien W, Kapsis K and Athienitis A. Manually-operated window shade patterns in office buildings: A critical review. Build. Environ. 2013; 60: 319-338.

8. Tzempelikos A and Athienitis AK. The impact of shading design and control on building cooling and lighting demand. Sol. Energy. 2007; 91: 369-382.

9. Van Den Wymelenberg K. Patterns of occupant interaction with window blinds: A literature review. Energy Build. 2012; 51: 165-176.

10. Deuk-Woo K, Meng P. and Cheol-Soo P. Comparative control strategies of exterior and interior blind systems. Light. Res. Technol. 2012; 44: 291-308.

11. Ji-Hyun K, Young-Joon P, Myoung-Souk Y and Kwang-Woo K. An experimental study on the environmental performance of the automated blind in summer. Build. Environ. 2009; 44: 15171527.

12. Jian, Y. An investigation into the impact of movable solar shades on energy, indoor thermal and visual comfort improvements. Build. Environ. 2012; 71: 24-32.

13. Zhang $Y$ and Barrett $P$. Factors influencing occupants' blind-control behaviour in a naturally ventilated office building. Build. Environ. 2012; 54: 137-147.

14. Reinhart CF. Lightswitch-2002: A model for manual and automated control of electric lighting and blinds. Sol. Energy. 2004; 71: 15-28.

15. Bodart M and De Herde A. Global energy savings in office buildings by the use of daylighting. Energy Build. 2002; 34: $421-429$.

16. Datta G. Effect of fixed horizontal louver shading devices on thermal performance of building by TRNSYS Simulation. Renew. Energ. 2001; 23: 497-507.

17. Claros ST and Soler A. Indoor daylight influence of light-shelf and model reflectance on lightshelf performance in Madrid for hours with unit sunshine fraction. Build. Environ. 2002; 37: 587 598. 
18. Mandalaki M, Zervas K, Tsoutsos T and Vazakas A. Assessment of fixed shading devices with integrated PV for efficient energy use. Sol. Energy. 2012; 86: 2561-2575.

19. Al-Tamimi NA and Fadzil SFS. The potential of shading devices for temperature reduction in high-rise residential buildings in the tropics. Procedia Eng. $2011 ; 21$ : 273-282.

20. ASHRAE. Handbook fundamentals. Ed. Atlanta. 5th ed. 2005.

21. Leslie RP. Capturing the daylight dividend in buildings: why and how? Build. Environ. 2003; 38: $381-385$.

22. Ali AAM and Ahmed TMF. Evaluating the impact of shading devices on the indoor thermal comfort of residential buildings in Egypt. Fifth National Conference of IBPSA-USA. Simbuild2012. Madison, Wisconsin, USA, 1-3 August 2012, pp. 603-612. IBPSA-USA.

23. David M, Donn M, Garde F and Lenoir A. Assessment of the thermal and visual efficiency of solar shades. Build. Environ. 2011 ; 46: 1489-1496.

24. Alzoubi $\mathrm{HH}$ and $\mathrm{Al}$-Zoubi $\mathrm{AH}$. Assessment of building facade performance in terms of daylighting and the associated energy consumption in architectural spaces: Vertical and horizontal shades devices for southern exposure facades. Energ. Convers. Manage. 2010; 51: 1592-1599.

25. Leon AL, Dominguez S, Campano MA and Ramirez-Balas $C$. Reducing the energy demand of multi-dwelling units in a Mediterranean climate using solar protection elements. Energies. 2012; 5: 3398-3424.

26. Reinhart CF, Mardaljevic J and Rogers, Z. Dynamic daylight performance metrics for sustainable building design. Leukos 2006; 3: 1-25.

27. Reinhart CF. Tutorial on the Use of Daysim Simulations for Sustainable Design, http://daysim.com/pub/Daysim3.0.Tutorial.pdf. (2010, accessed 10 September 2010).

28. Reinhart CF and Walkenhorst $O$. Validation of dynamic RADIANCE-based daylight simulations for a test office with external blinds. Energy Build. 2001; 33: 683-697.

29. Kleindienst S, Bodart M and Andersen M. Graphical representation of climate-based daylight performance to support architectural design. Leukos 2008; 5: 39-61.

30. Andersen M, Mardalievic J and Lockley SW. A framework for predicting the non-visual effects of daylight - Part I: photobiology-based model. Light. Res. Technol. 2012; 44: 37-53.

31. Nabil A and Mardaljevic J. Useful daylight illuminances: A replacement for daylight factors. Energy Build. 2006; 38: 905-913. 
Climate-based daylight analysis of fixed shading devices in an open-plan office

32. Reinhart CF and Wienold J. The daylighting dashboard-A simulation - based design analysis for daylit spaces. Build. Environ. 2011 ; 46: 386-396.

33. Mardaljevic J, Andersen M, Roy N and Christoffersen J. Daylighting metrics: Is there a relation between useful daylight illuminance and daylight glare probability? Proceedings of the 2012 Building Simulation and Optimization Conference (ed J Wright and M Cook). Loughborough, Leicestershire, UK, 10-11 September 2012, pp. 189-196. IBPSA-England.

34. EN 12464-1: Lighting of Workplaces: Indoor workplaces. 2001. 